\title{
Informing augmented memory system design through autobiographical memory theory
}

\author{
Elise van den Hoven · Berry Eggen
}

Received: 3 October 2005/Accepted: 1 September 2006/Published online: 17 July 2007

(C) Springer-Verlag London Limited 2007

\begin{abstract}
Autobiographical memory (AM) is the "memory for the events in one's life" [1]. Often it is assumed that in order to remember all those events, you just need to record everything and when you replay these recordings you will remember those events. You can compare this with a library metaphor that has been used to explain AM according to the record-keeping approach. However, after many years of AM-research it was concluded that AM is stored in a different manner, namely according to the constructionist approach, which often is initiated by memory cues. This paper explains these AM theories, surveys literature on existing augmented memory systems and describes our own work in this area. All this input is combined into eight design recommendations for future augmented memory systems.
\end{abstract}

Keywords Autobiographical memory .

Recollecting memories - Interactive system design .

Augmented memory systems

\section{Introduction}

Most people are actively dealing with their personal memories. Take for example the woman who just returned

E. van den Hoven $(\square)$

Department of Industrial Design,

Eindhoven University of Technology,

Den Dolech 2, HG 2.53, P.O.Box 513,

5600 MB Eindhoven, The Netherlands

e-mail: E.v.d.Hoven@tue.nl

\section{B. Eggen}

Department of Industrial Design,

Eindhoven University of Technology,

Den Dolech 2, HG 2.39, P.O.Box 513,

5600 MB Eindhoven, The Netherlands from a holiday. Probably she will talk about her experiences with various people, which in fact is the rehearsal and perhaps the fixation of her holiday memories. When she refers to other related experiences and events in the same conversation she is trying to relate her new memories to other existing memories, thereby working on her old memories at the same time. There even is a fair chance that her listeners are doing the same thing. Reminiscing is a recurring process, continuously shaping people's personal histories and identities.

This paper gives an overview of issues and answers that are relevant to people who are interested in recollecting memories or in designing augmented memory systems. These issues were subdivided into theory, on human memories and memory cues (Sect. 2), and practice, presenting a literature overview of (studies on) augmented memory systems (Sect. 3). The lessons learned from literature and findings of our own research efforts into the design of an augmented memory system are combined to describe a set of eight design recommendations for future augmented memory systems (Sect. 4). The paper ends with conclusions in Sect. 5.

\section{Autobiographical memory}

As Bush [2] already stated in his Memex article, we should study the associative way in which our mind works to create analogies that improve recording and retrieving in an augmented memory system. Since this paper is concerned with people who are recollecting personal experiences, autobiographical memory (AM) is the most relevant (longterm) memory type to study.

The definition of AM is "memory for the events of one's life" [1], which includes all the people's memories that 
have something to do with themselves. Episodic memory stores information relating to personal experiences, but episodic memories can exist without being autobiographical and vice versa. It is not yet known how these two memory systems relate to each other, although it is certain that they have a large overlap in memories [3].

Various long-term memory types have been proposed over the past years (see [4] for an overview), each memorypair is seen as independent of other memory systems. For example, prospective and retrospective memory are related to the process of remembering, since they are concerned with the future and the past: prospective memory helps remembering to carry out intended actions and retrospective memory remembers past events.

\subsection{Functions of autobiographical memory}

According to [5] six functions of autobiographical memory can be distinguished:

1. The construction and maintenance of the self-concept (who you think you are) and self-history (what you have experienced in life), which shapes the personal identity.

2. Regulating moods, e.g., when someone is feeling down it can help to think of positive memories.

3. Making friends and maintaining relationships by sharing experiences, e.g., when you share personal memories with someone this creates a bond and as a result the other person might feel the need to share his or her personal experiences with you too.

4. Problem-solving based on previous experiences, e.g., if someone encounters a problem, memories of related experiences, actions and results are used as input to overcome the current problem.

5. Shaping likes, dislikes, enthusiasms, beliefs and prejudices, based on remembered experiences.

6. Helping to predict the future based on the memories of the past.

Note the wide range of AM-functions, from solely internal usage, to communication between people. It is important to realize that for none of the above-mentioned functions the absolute truth behind the memory is needed. For a long time it was assumed that memories represent the way events really occurred, which resulted in a memorystorage theory called the record-keeping approach.

\subsection{Record-keeping approach}

The oldest theory for recollection storage and retrieval (already described by the Greek philosopher Plato) is called the record-keeping approach [6]. The main idea of this approach is based on the metaphor that like a library is filled with books, human memory is filled with memories. In this library each book stands for a memory and every new experience creates a new book. Searching for a book represents the retrieval process and in case a stored book is not found, one speaks of forgetting. According to this theory the more memories a person has the harder it gets to retrieve the right memory.

The literature examples in Sect. 3.1 show that projects exist which try to "record life" in order to "store people's memories". These projects are based on the record-keeping approach.

\subsection{Constructionist approach}

The record-keeping approach is particularly suitable to "preserve the past", while the constructionist approach [6] is more suitable for "anticipating the future". This theory describes a constantly adapting memory system. Since memories change connections between ideas and concepts, mainly recent events, patterns and unique events are stored. By repeating or rehearsing events (talking about them or experiencing similar events several times, such as eating breakfast every day) the connections get stronger (e.g., between cereals and breakfast). This explains why a person remembers information relating to her expertise with less effort compared to new information; the ideas, concepts and connections are already present.

Memory recall happens by means of reconstruction. Take the example that someone tries to remember what she did on a specific Friday around 6 p.m. First, she goes back to what she usually did on Fridays, she went to work. Usually she stopped working at about 5:30 p.m., thus she must have been on her way home by 6 p.m. Unless it was a very exceptional Friday, this person does not remember at what time she went home that day, but she infers it from her regular pattern. Although this person might be sure that she was on her way home that day, she might have had a day off, instead.

Because of this reconstruction process memories change over time according to current knowledge and beliefs and no two recollections of a specific event are the same [7]. Forgetting occurs when reconstruction is no longer possible due to too many adaptive changes.

Currently, the constructionist approach is taken forward by the majority of memory researchers (e.g., as in connectionism [8]). This theory is supported by both psychological and neurophysiological investigations [6]. From this constructionist approach and the general knowledge of the relation between memories and emotions [9], it follows that central components in memory foundation are: prior knowledge, personal importance and affect [10]. In addition, enduring memories should be: strongly emotional, a turning point in the life of the individual or (remain) rel- 
atively unique [11]. The category "unique memories" contains a specific type of memory which is remembered well, namely Flashbulb Memory. Flashbulb memories are memories for dramatic world events, such as the death of Lady Diana, the Princess of Wales, and the 11th of September 2001 World Trade Center attacks. Those memories are vivid, detailed and long lasting [12].

According to [9], in general, pleasant events are recalled better than unpleasant events. For more information on the state of the art with respect to models trying to explain the relations between emotion and memory, see for example [13].

\subsection{Levels of specificity}

A recent contribution to the constructionist theory on storage and retrieval, relevant for the design of augmented memory system, comes from a model that describes three levels of specificity of autobiographical memories [14]:

1. Lifetime periods consist of temporal knowledge about the duration of a certain period and thematic knowledge about common features of this period. Often such a period lasts for years, for example "when I was at school". Several lifetime periods may be grouped to form a higher order theme, such as "work" or "relationships".

2. General events cover both repeated and single events, which lasted for days up to months, for example "I used to play with my best friends after school". Groups of general events can form clusters, such as "learning to ride a bike" or "being best friends with X".

3. Event-specific knowledge (ESK) concerns detailed information unique to a single event (which can again be subdivided into "microdetails"), with a duration of seconds or hours, for example "once when sleeping over at my friends house I fell and hurt myself when trying to do a somersault". ESKs are often accompanied by "images that pop into mind" and ESKs are presumably used to convince listeners that the speaker really remembers.

It is thought that lifetime periods and general events are stored in a different structure in the brain compared to ESKs, since ESKs, and also the links between general events and ESKs, are easily forgotten except for rehearsed memories. Lifetime periods and general events are remembered better than ESKs [14].

Memory retrieval, as demonstrated in laboratory conditions, happens in cycles. This means that recollecting starts with a cue or a short memory description, a dive into long-term memory and then a cycle starts going through lifetime periods, general events and ESKs. During and after each cycle the supervisory attentional system (SAS) checks whether the information retrieved does not conflict with the constraints imposed on the memory search, which include the mental model of the task, the current self concept and the active themes, goals, and plans of the self. The SAS determines to inhibit or increase certain activities and eventually to terminate the search [7].

\subsection{Cuing memories}

In previous sections it was shown that people reconstruct events according to the constructionist approach. This indicates that the memory itself cannot be stored in an augmented memory system, because a person is needed to recreate this memory for every recollection. In order to help people reconstruct a memory one can cue memories and these cues could be stored in an augmented memory system. A cue (or trigger) is a stimulus that can help someone to retrieve information from long-term memory, but only if this cue is related to the to-be-retrieved memory. The stimuli most often used in studies are photos, smells or text labels. But anything could be a cue (a spoken word, a color, an action or a person), as long as there is a link between the cue and the to-be-remembered event. A combination of cues increases the chance of retrieving a memory, especially when a subject in a cued-recall experiment has to perform activities, which have to be remembered later, such as to write with a pen or close a door [8, 15].

In general, there are two types of cue-usage, namely generative and direct retrieval, respectively caused by a conscious, cyclic memory search process and unconscious memory cuing [14].

What kind of cues might work best for memory retrieval? Three memory-type categories exist on this topic, namely context-, state- and mood-dependent memory [8]. They are all based on overlap of internal or external conditions during the encoding of a memory and the retrieving of the same memory. The first example is called the encoding-specificity principle [16] and falls within the category contextdependent memory. Both principle and category refer to the idea that a memory is easier to retrieve if the physical context during retrieval is (partly) the same as the physical context during encoding. A famous example of contextdependency comes from Godden and Baddeley (1975, as mentioned in [8]). They instructed divers to learn words either under water or on the beach. They found that the number of words recalled correctly was high if the retrieval context was the same as the encoding context, meaning if the words were learned underwater they were best recalled underwater and the same held for the beach condition. The performance dropped significantly when the context was changed from underwater to beach or vice versa.

The second category explaining a relation between cue and retrieval result, is called state-dependent memory, 
including the state-dependency effect [8]. This category does not focus on the external context of the person remembering, but the internal one, which is tested often with participants who are drugged or drunk. In general, it appears that when something is learned when drunk, it is best remembered when drunk.

The third and last category is called mood-dependent memory, which states that retrieval is best if the mood at recall is similar to the mood at encoding, because of hypothesized distinct emotion modes [9]. Although this effect, which can be studied with depressed people for example, has been found to be strong for free-recall, the effect was not present in cued recall [4].

\subsection{Forgetting}

Sometimes cuing does not help recalling a specific memory, and then one might speak of forgetting. Although forgetting is not yet understood completely, there is evidence in support of cue-dependent forgetting, which means that memories are still present in memory but they cannot be accessed, i.e., the right cues cannot be found [17].

\subsection{Conclusions on theory overview}

Recollecting memories from autobiographical memory, "memory for the events of one's life" [1], works by means of reconstructing memories, which in turn can be initiated by memory cues. Due to changes in, e.g., personal belief systems, the outcome of a memory reconstruction can change over time. Therefore a memory is not always a factual representation of what actually happened but it can be a representation of how the event at this point in time reflects the goals of autobiographical memory, such as creating a personal identity or maintaining relationships.

\section{Augmented memory system literature}

After the introduction into autobiographical memory theory (Sect. 2) this section gives an overview of relevant literature on augmented memory systems, or systems that help people recollect memories. Since this is quite a broad topic, the literature is divided into four groups. Each group consists of studies around a central theme in recollecting: (1) recording life, (2) reminding tasks, (3) creating cues, and (4) augmented memory systems (which can also include recording life and creating cues as tools for recollecting). The studies discussed within these categories can inspire future work on any type of augmented memory systems. As will be shown some even formulate recommendations for designing such systems.

\subsection{Recording life}

Based on the AM theories mentioned in Sect. 2 human memory does not "record life" and even if a system would record an event these recordings do not have to be the same as the personal memories of this event. However, recording a person's life can be the start of recollecting memories, because when the recordings are later re-experienced they can cue the viewer. The projects mentioned below do not focus on cuing memories, but more on other aspects of having a database of facts, such as looking up appointments. The process of recording life is made possible with an automatic and, in these cases, electronic "diary", such as the familiar [18]. This system contains sensors, cameras and microphones, that try to record everything the user perceives or experiences. The familiar aims at learning to record the right event in the multimedia diary. A similar study was done for the workspace [19], making use of cameras, sensors, displays and RFID tags, where specific activities with artifacts are recorded and replayed in order to make the user learn the location of that artifact. This project aims at extending human memory by recording events that are later shown to the user. The forget-me-not device [20] automatically records several types of office behavior, such as meeting people, using the PC and making telephone calls. The user decides to look through the stored events later on a portable device, when she tries to remember a name of a colleague or the location of a document.

Starner et al. [21] created a remembrance agent which is a text-based augmented-reality system. This agent is fed by a database of information recorded by means of wearable computing that is partly integrated in special glasses and partly in special clothing. The wearable computing system records audio and video, performs face recognition, detects location and body responses of the wearer. The remembrance agent can be addressed by typing in commands and it can make suggestions to the wearer.

Apart from above-mentioned studies there are indications that "recording life" is seen as one of the great challenges for future research [22].

In addition to these projects, in which recordings of memories are made automatically without user control, there are also projects in which the user can decide what to record and what not. The very first ideas were already written down by Bush [2] who proposed the "memex": "a memex is a device in which an individual stores all his books, records, and communications, and which is mechanized so that it may be consulted with exceeding speed and flexibility. It is an enlarged intimate supplement to his memory". According to Bush this memex looks like an ordinary desk. A more recent description of such an idea is called "The Teddy" [23]. The Teddy is a small portable 
device that each individual carries around his whole life. This device can record anything and the interaction necessary for retrieval, of e.g., telephone numbers, ID-numbers, or bank accounts, goes via speech recognition.

The previous two examples consisted of ideas, while the following projects were implemented to record a part of a person's life. The rememberer [24] is situated in a science museum and the benefit for the user is that she can decide which information offered in this museum she wants to have access to later. The user gets a portable PDA or an RFID card (both with the same functionality), that can be used to select interesting exhibits. When doing so four photos are shot from the user at the specific stand. When the user leaves the museum she receives a fridge magnet with a unique URL, which links to a website with all the personally requested information and the photos. The MyLifeBits project [25] aims at providing software for people who record their own life by collecting all personal documents and media online. In the near future such software could be the basis for an augmented memory system.

\subsection{Reminding tasks}

Reminding people of tasks concerns prospective memory (see Sect. 2), which helps people remember things they have to do, like the well-known knot tied in a handkerchief. Examples of investigations in this area include the MemoClip [26]: a pin worn by the user reminds of a locationbased task when this user walks into a specific area. Another example is the CybreMinder [27], a system using location sensors, cameras and speech recognition, which reminds users of specific conditions, e.g., to take an umbrella when going outside if it is cloudy. This type of function is not so much related to remembering in the sense of reconstructing an event, as well as remembering facts. Therefore, the AM-theory is not needed per se, but could be used to facilitate remembering these facts, e.g., by using cues. This is done in the following project. Memory Glasses [28] go along with a jacket full of computing, sensing and a speech recognition system. Reminders, depending on the context, are projected on the inside of the memory glasses.

Note that the above-mentioned projects all require from the users to insert the events they want to be reminded of later.

\subsection{Creating cues}

People use memory cues to help them remember (see Sect. 2.5). One way to create cues is to use a recording of an event, which is shown in the first project [29]. A historyof-use of digital artifacts was created, where the traces of usage implicitly could help people remember what happened to the artifact. Another way of creating cues is by making them explicit and let the user decide how to use this knowledge. This was done in the Memory Palace project [30] that used software to recreate a mnemonic device. The idea is that it helps people's recall if they place their to-be-learned material in an imagined house. Later when they recollect the mental images of the rooms are used as cues to help recall.

One aspect of creating cues was not covered in any of the studies mentioned in this paper and that is how an augmented memory system could extract information from an event that later could be used as a cue for recollection.

\subsection{Augmented memory systems}

Browsing through digital photos is often the basis of an augmented memory system as can be seen in Table 1 . This table gives an overview of devices that are explicitly designed to support recollecting or to augment human memory. The text below explains the individual systems in some more detail.

(It should be noted that in some cases the applications described are mere concepts which are not implemented as working demonstrators. ${ }^{1}$ )

The Personal Digital Historian [32] makes use of tabletop projection. Photos can be browsed by touching the categories who, what, when and where that are presented as text and based on metadata input. The system is especially suitable for multi-user interaction, since people can sit around the circular table and turn the GUI in any direction. However, the ceiling projector fixes it to one location.

PenPal [33] is a communication device for children created for a design competition. With the PenPal children can take photos and add sounds or voice annotations, they can create and send images across the internet. The prototype consisted of an LCD touch screen device with slots for memory cards, a camera and a microphone.

The StoryTrack [34] is a portable touch-screen device which is meant for enhancing storytelling. The user can browse and display digital photos and add and play voice annotations on the prototype. The touch screen was not used; instead the authors mounted new input controls on the edges of the device. The user interface contained a display area, a scrollable thumbnail-overview and a section showing information and controls for possible annotations associated with the digital photo currently displayed.

The Storytable is an art installation that combines digital photos, videos and songs [35]. This table contains three

\footnotetext{
${ }^{1}$ Commercial devices that can show digital photos and e.g., texts are electronic books, or e-books, such as SoftBook Reader and Rocket eBook [31], laptops, mobile phones and PDAs.
} 
Table 1 Augmented memory systems, in the same order as the description in this paper, are categorized by the media types they support

\begin{tabular}{lccccc}
\hline & Photo & Text & Sound & Video & Artifact \\
\hline Personal Digital Historian [32] & $\times$ & $\times$ & & & \\
PenPal [33] & $\times$ & $\times$ & $\times$ & & \\
StoryTrack [34] & $\times$ & $\times$ & $\times$ & & \\
Storytable [35] & $\times$ & $\times$ & $\times$ & $\times$ & \\
PhotoShare [36] & $\times$ & & & & \\
memoryBox [37] & $\times$ & & & & $\times$ \\
Rosebud [38] & & $\times$ & & & $\times$ \\
MiMe [39] & $\times$ & & & & $\times$ \\
Memory Box [40] & & & $\times$ & & $\times$ \\
POEMs [41] & $\times$ & $\times$ & & $\times$ & $\times$ \\
Object scanner [42] & $\times$ & $\times$ & $\times$ & $\times$ & $\times$ \\
Living Memory Box [43] & $\times$ & $\times$ & $\times$ & $\times$ & $\times$ \\
\hline
\end{tabular}

hidden PCs and three visible PC screens. The project aimed at the elderly user and was designed to have two large buttons in the vicinity of each screen. With one of these buttons the user can stop videos and songs from floating over the screen. The other button starts playing the currently selected media item. Typed stories can also be added to the system.

The PhotoShare application [36] makes use of a projection on a table for displaying digital photos. The user interacts via wooden blocks that can be put on top of a projected thumbnail in order to enlarge it in an appointed location, both local and remote.

A project called memoryBox [37] developed a concept supporting random browsing and creating an interactive experience. Clothing buttons are each linked to one digital photo, just like the wooden blocks in the PhotoShare application. When the user runs her hand through the buttons in the memoryBox, the photos appear temporarily on the display inside the box cover.

The Rosebud project [38] links children's stories to keepsake artifacts, in this case stuffed animals. The children can type stories on their PC, which are "told" to the animal. The animal can even react to the stories by asking questions or by moving, e.g., by nodding its head or clapping its paws. Rosebud wants to teach children to treat their stuffed animals as listeners of their stories. In this way, a learning environment is created to improve children's verbal skills.

Artifacts can also be attached to souvenirs which is shown by MiMe [39]. A prototype was built based on their GlowTags-concept, which concerns small artifacts that can be linked to intimate media, such as a printed photo. Two people could have a copy of the same photo, each having a GlowTag. Then when one person touches the photo, the other person's tag could start to glow, showing an intimate connection. The tag could also glow when the person in the photo has his/her birthday.
HP's Memory Box [40] "was built to illustrate the possibility of recording and attaching stories to memorabilia kept in a box". The project focused on recording and playing spoken stories which were associated with a limited number of artifacts.

POEMs [41], which stands for physical objects with embedded memories, is a concept in which physical artifacts are linked to digital "memories", such as digital photos, audio and video. Two scenarios and a video were created.

British Telecom created a prototype of a scanner that can scan artifacts, such as souvenirs [42]. When an artifact is scanned a PC plays the attached media, like e-mail, text messages, websites and the TV shows photos, videos and audio.

Work from Stevens et al. [43] focuses on parents who want to preserve memories of and for their children. Based on a series of interviews with parents, design activities and focus groups they designed the so-called living memory box, which makes it possible to link virtual information to physical artifacts. This linking is done by putting an artifact in a dedicated box and by selecting media-files on an attached display.

The studies mentioned above worked on devices or artifacts to help people recollect their autobiographical memories. Some of them remain concepts, while others have been developed into working prototypes. Stevens et al. [43], presented the following recommendations for the design of a future augmented memory system:

1. Develop the process of annotating or organizing memories into an activity of personal expression.

2. Make the inclusion of practically any artifact possible (which is in line with our earlier findings, see Sect. 4.1).

3. Bring the interaction away from the PC.

4. Develop "natural" interactions (i.e., touch and voice). 
5. Encourage storytelling at any point.

6. Assure the capability of multiple "voices".

7. Create unique experiences, especially for creating and viewing annotations.

\subsection{Conclusions on literature overview}

The number of studies on augmented memory systems shows that the topic of helping people remember is a popular one. Despite the popularity the authors are not aware of studies that mention (autobiographical) memory theory or used it to inform their design. Most studies therefore do not (explicitly) identify that cues are important for recollecting, nor do they use the different levels of specificity of memories.

The majority of examples focuses on "recording" memories and not on "retrieving", of which the latter could be based on "cuing" or "reconstructing", memories. Some studies do not even make a distinction between these processes, perhaps assuming that the process of recording memories can automatically make people recollect.

All media types, from digital photos to physical artifacts, can be used as memory cues in an augmented memory system, although none of the papers explicitly mentions cuing as such.

\section{Design recommendations}

Based on the literature overview of Sect. 2 we can conclude that the natural way to recollect memories is by means of cues and this can be supported by an augmented memory system. Therefore our first recommendation (R-I):

$R-I$ An augmented memory system should support memory cuing. It could cue the user automatically and continuously, as in daily life.

The design recommendations given by Stevens et al. [43] are a first set of guidelines that can be used for the design of a future augmented memory system. In the following sections these recommendations will be expanded derived from our research on creating an in-home memoryrecollection support [45]. The focus is on the interaction through physical artifacts to which memories are linked: souvenirs (Sect. 4.1), the implemented Digital Photo Browser demonstrator (Sect. 4.2) and autobiographical memory theory and experimentation (Sect. 4.3).

\footnotetext{
${ }^{2}$ Within the context of artificial intelligence case-based reasoning is used as a method to show how the reconstruction of memories could work [44, pp 8-9].
}

\subsection{Souvenirs}

One promising memory cue type is souvenirs, because physical souvenirs can create a counterbalance for the increasing digitization of memory cues (such as digital photos and digital video footage). The usage of souvenirs as memory cues is studied in the field of autotopography [46]. Autotopography studies personal collections of physical artifacts that serve as a memory landscape to the owner. These artifacts, such as photos, souvenirs, furniture or jewelry, physically shape an autobiography because they link to memories that are important for the owner, and therefore these artifacts are important too. This link though is invisible and often unknown to other people. The collection of artifacts, its arrangement (such as a home altar), and its location (stored in the attic or placed in the middle of the living room) represent a part of the owner's memory, history and thus identity. At the same time, these artifacts might represent desire, identification and social relations, establishing a form of selfrepresentation.

In addition to some descriptive work on autotopography no investigations have been done on the real-world implementation of this concept. There is no data on the number of autotopographical artifacts, which artifacts can become autotopographical or what types of memories are attached to them. Csikszentmihalyi and Rochberg-Halton [47] did study which artifacts people have at home, but they did not ask which artifacts had a souvenir-meaning. They asked for favorite artifacts and then wanted to know why these artifacts were favorites (the number one reason was because of memories). We were interested the other way around, which physical artifacts are available in home that can be used as souvenirs because they cue memories. Therefore, we conducted a questionnaire study [45] of which the most relevant conclusions are summarized below.

People appeared to have a collection of souvenirs at home, on average over 50 and most of these souvenirs could be found in the living room and the study. This shows that souvenirs are readily available for use together with an augmented memory system. Three categories of souvenirs were identified: holiday souvenirs, heirlooms (including furniture) and gifts. All three categories made the participants recollect memories when they looked at it, meaning they served as memory cues for them. Threequarters of the participants had media-type associations with their most valuable souvenirs, on average 24.3 associations per souvenir, such as photos, videos, smells, sounds, texts. Therefore we can conclude that souvenirs should be considered as powerful memory cues in an augmented memory system, which is our second recommendation (R-II): 
$R$ - $I I$ Include souvenirs in an augmented memory system as memory cues.

\subsection{Digital Photo Browser demonstrator}

In parallel to the studies mentioned before, we also developed our own augmented memory system that supported browsing, searching and sharing digital photos in the home environment and it was called the Digital Photo Browser. This team-effort was carried out in the Phenom project, which was part of the Philips research program on ambient intelligence [48].

Based on the results of the souvenir study mentioned in the previous section this Digital Photo Browser supported souvenirs that cued personal recollections and simultaneously could be used as tangible links to digital media, in this case digital photo collections (see Fig. 1). One example activity concerns placing a souvenir on the table, which would trigger the handheld touch-screen device to display all the photos linked to the souvenir in the photo roll (on the right of the screen). In case you were interested to view one of these photos that scroll by, you could drag it to the center of the screen for a personal enlargement. If you decided that you wanted to show a particular photo to your guests, you could drag it to the thumbnail of the TV (on the left of the screen) and it would be displayed on the television. This supports both public and private photo browsing. Photos can also be displayed on a digital photo frame in the cupboard or can be sent to a photo printer, all wirelessly.

For more details on the working Digital Photo Browser demonstrators, see [45, 49-52].

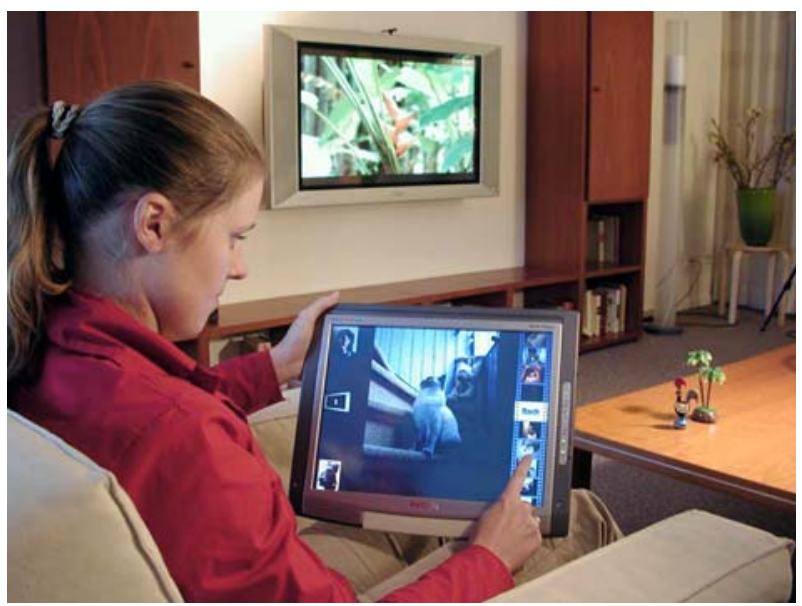

Fig. 1 The Digital Photo Browser demonstrator with souvenirs as tangible artifacts (photo: Philips Research)
More and more people create digital recollection-cues, such as digital photos and digital video footage. Therefore the design of an augmented memory system should be based on a digital device in order to be able to store and play those digital media. On the other hand, there is still the opportunity to combine the digital cues with the physical ones, like the souvenirs in the Digital Photo Browser demonstrator. This combination has several benefits, such as using the physical artifacts people already have that are often valuable to them. Another benefit is that souvenirs are traditionally used to cue memories, therefore helping the recollection process in a natural way. The combination of physical and digital artifacts might also help people who are not experienced in working with digital devices in their interaction with those new technologies.

For the Digital Photo Browser the link between souvenir and photo seems also useful since often souvenirs are bought on a holiday (see previous section) and the buyer also creates the digital photos there, which later can be linked easily to the corresponding souvenir. Therefore the buyer and photographer, who is also the user of the Digital Photo Browser, will automatically have a mental model linking the souvenirs to the digital photos.

Physical artifacts representing shortcuts to subsets of digital photos, which is called tangible interaction or a graspable/tangible user interface [53,54], were chosen for the following reasons: (1) quick access to photos, (2) a selfchosen artifact is the link, so there is room for personalization, (3) people already know beforehand the mental link between the artifact or souvenir and the photos, since they created the link themselves, (4) the interaction style makes it possible to link physical with virtual, making digital photos tangible, (5) at the same time the souvenirs provide memory cues to the user, (6) the affordances of touching and releasing a physical artifact serve as natural start and stop events in the interaction [55] and (7) souvenirs might facilitate storytelling, or sharing recollections [56]. Because of these reasons the following recommendation can be formulated:

$R$-III Include souvenirs in an augmented memory system in the same way as tangible artifacts in tangible interaction.

Physical artifacts, such as furniture, souvenirs, artifacts and printed photos, should be linked to the device and maintain their original function. The user can decide what she wants to associate to the augmented memory system and the options should include all kinds of media, ranging from a piece of text to a complete bodily experience. In this paper the focus is on media that are currently available for the regular user, namely: sounds/music, video, photos/ pictures, physical artifacts/souvenirs/keepsakes/mementos/ heirlooms/furniture, and text. 


\subsection{Autobiographical memory}

Section 2.1 mentioned the diverse functions of autobiographical memory, including problem solving, regulating moods and creating and maintaining relation ships. A future augmented memory system could in theory support all these functions. The question however is whether people will use such a device for all these functions, since the focus of the examples in this paper is predominantly on supporting personal identity and sharing experiences with other people, only two of the six AM-functions.

$R-I V$ Choose explicitly which functions of autobiographical memory should be supported by the augmented memory system and base the design of the system on these decisions.

Most augmented memory system examples mentioned in Sect. 3 did not explicitly choose a particular AM-function that should be supported. Most examples focused on implementing the recording part of the remembering process, without even mentioning retrieval. For an optimal augmented memory system the selected function and recollection process need to be optimized. For example, an augmented memory system focusing on personal identity, needs a different recording and retrieval process, compared to a system recording one's life.

$R-V$ Choose which part of the remembering process should be supported by the augmented memory system: recording and/or retrieving memories. Design these with the requirements of the chosen function (R-IV) in mind.

An interesting remark resulting from the Maypole project [57] was made about the truthfulness of physical versus digital photos. A lot of people do not know whether to believe the contents of a digital photo, since anybody nowadays can change or edit them with software on their own personal PCs. But, according to Maypole, printed photos do also not represent real everyday life in the sense that people go to great lengths to make a family look happy, successful and prosperous in a photograph, whether this is true or not.

From the literature mentioned in Sect. 2 it was learned that memories do not stay the same over time, they are, just as photos, not per se a carbon-copy of reality. People's beliefs and contexts change and therefore the reconstruction of memories can change as well. This is an important fact for an augmented memory system, since it implies that this device is really only a support for the user. Ultimately, it is the user who has to recall the memories herself. Therefore:

$R$-VI An augmented memory system should not necessarily present recorded material as the "only" instanti- ation of what really happened, since this might interfere with the actual recollections of the user.

In addition to remembering, recollection also comprises rehearsal. Every time a memory has been remembered (thought about or communicated) this information either will be stored more securely, or the information changes, because the context has changed. This implies that adding, deleting or changing metadata to an augmented memory system should be flexible. People might change their mind on the story behind a photo or souvenir, which requires a metadata system that can easily be adapted. Perhaps it could be interesting to keep an interaction history, such as the one described in [50], which keeps certain changes made by the user, e.g., to digital photos, as metadata.

$R$-VII Create a metadata system that can be changed easily by the user.

The theory on AM's levels of specificity (Sect. 2.4) assumes that the process of recollecting starts with the highest of three levels of specificity, life-time periods, and continues to general events, ending with ESK. Depending on the goal of the augmented memory system the design should focus on different levels of specificity:

$R$-VIII If an augmented memory system has the goal to support people's remembering as much as possible, it should focus on ESK. If the goal is to support the general structure of memory, the focus has to be on lifetime periods and general events. If the system should support the user through the whole process of remembering the presented information should relate to the recollection cycle with its supervisory attentional system (SAS) and all three levels of specificity.

An augmented memory system for recollection of everyday memories benefits most from context-dependent memory cues (Sect. 2.5). Such cues could consist of anything physically related to the external context of the to-beremembered event, ranging from photos to sounds to physical artifacts, which supports R-II.

Within the context of the encoding-specificity principle a real-life cuing experiment was realized in order to test the efficiency of memory detail (or ESK) recall for five cuetypes: photos, smells, sounds, souvenirs and videos [45, 58, 59]. Against expectation, text cues (the no-cue condition) generated significantly more ESKs than the cued condition. Our explanation for this unexpected result was that cues make people focus on what they perceive instead of trying to think of other memories that might be related. For example, when asking about a specific event, while giving the participant a photo, this person might focus on photorelated memories instead of freely recall any related memories. Therefore, if the goal is to remember as much as 
possible text should be the main cue type in an augmented memory system.

However, it might be dangerous to restrict to text (based on this experiment) since there are more dimensions to recollecting that were not tested. Examples of these additional dimensions are: pleasure while recollecting, the ability to change the user's mood, the intensity of the memory, the effect of cues a long time after the memorycreation, the speed of the memory-recall and perhaps personal preferences for certain cue types. Although those dimensions were not investigated it is assumed that e.g., the pleasure of the recall process is bigger with photos than with only text, especially in a situation where someone is communicating her memories to somebody else. The pleasure aspect was often apparent during the summative evaluation of the Digital Photo Browser [45] in both storyteller and listener, shown by smiling faces, pointing fingers towards the photos and concentrated conversations. In addition, cues might have different effects for the different age groups [60]. Therefore, more research is needed to investigate these other dimensions of the recollection experience.

\section{Conclusions}

It was long assumed that memories are stored as complete events and that whenever you recollect a memory, the complete story of the event as it happened, will come back to you. This is not how autobiographical memory works. Remembering is a process in which you reconstruct what happened, based on the strength of the relations between concepts stored in memory. This means that what you recollect does not have to be what happened at that specific point in time, since the relations between concepts or the concepts themselves can change over time or become inaccessible (which we experience as forgetting). Therefore an augmented memory system cannot store memories.

Users of such a system should be able to use cues to initiate or facilitate this reconstruction process. They should (implicitly) steer the recollection process to fit their current "vision" on the events that have occurred, because there can be reasons behind memory changes and therefore they should be supported. Examples of memory cues are photos, sounds, smells, texts and souvenirs.

Interesting areas for future research concern how the different functions of autobiographical memory can be supported by dedicated augmented memory systems and what the relations are between memory cues used and the (kind and strength of the) memories that are recollected (e.g., do the cues become memories?). Of course, longitudinal studies of augmented memory systems should give insights in all related aspects of everyday recollecting (e.g., the actual use of cues, physical and digital media).
Acknowledgments The authors would like to thank I. Wessel for introducing us to and guiding us through the field of autobiographical memory, A. Kohlrausch and M. Rauterberg for their support during the mentioned studies and the other members of the project team that created the Digital Photo Browser: E. Dijk, N. De Jong, E. Van Loenen, D. Tedd, D. Teixeira and Y. Qian.

\section{References}

1. Conway MA, Rubin DC (1993) The structure of autobiographical memory. In: Collins AF, Gathercole SE, Conway MA, Morris PE (eds) Theories of memory. Psychology Press, Hove, pp 103-137

2. Bush V (1945) As we may think. Atl Mon 176(1):101-108

3. Conway MA (2001) Sensory-perceptual episodic memory and its context: autobiographical memory. Philos Trans R Soc Lond B 356:1375-1384

4. Eysenck MW, Keane MT (2000) Cognitive psychology: a student's handbook. Psychology Press, Hove

5. Cohen G (1996) Memory in the real world. Psychology Press, Hove

6. Guenther RK (1998) Human cognition, upper saddle river. Prentice-Hall, USA

7. Conway MA (1996) Autobiographical knowledge and autobiographical memories. In: Rubin DC (ed) Remembering our past: studies in autobiographical memory. Cambridge University Press, Cambridge, pp 67-93

8. Baddeley AD (1999) Essentials of human memory. Psychology Press, Hove

9. Oatley K, Jenkins JM (1996) Understanding emotions. Blackwell, Cambridge

10. Rubin DC (1996) Remembering our past. Cambridge University Press, Cambridge

11. Neisser U (1982) Memory observed: remembering in natural contexts. WH Freeman, San Francisco

12. Brown R, Kulik J (1977) Flashbulb memories. Cognition 5:73-99

13. Philippot P, Schaefer A (2001) Emotion and memory. In: Mayne TJ, Bonanno GA (eds) Emotions. Current issues and future directions. The Guilford Press, New York, pp 82-122

14. Conway MA, Pleydell-Pearce CW (2000) The construction of autobiographical memories in the self-memory system. Psychol Rev 107:261-288

15. Engelkamp J (1998) Memory for actions. Psychology Press, Hove

16. Tulving E (1983) Elements of episodic memory. Oxford University Press, Oxford

17. Tulving E (1974) Cue-dependent forgetting. Am Sci 62:74-82

18. Clarkson B, Mase K, Pentland A (2001) The familiar: a living diary and companion. In: Proceedings of the ACM conference on human factors in computing systems (CHI'01), pp 271-272

19. Ikei Y, Hirose Y, Hirota K, Hirose M (2003) iFlashback: a wearable system for reinforcing memorization using interaction records. In: Proceedings of human-computer interaction international (HCI-Int. 2003), pp 754-758

20. Lamming M, Flynn M (1994) "Forget-me-not" intimate computing in support of human memory. In: Proceedings of FRIEND21, '94 international symposium on next generation human interface

21. Starner T, Mann S, Rhodes B, Levine J, Healey J, Kirsch D, Picard R, Pentland A (1997) Augmented reality through wearable computing. Presence 6(4):386-398

22. Fitzgibbon A, Reiter E (2003) "Memories for life": managing information over a human lifetime, Retrieved 14 Mar 2007, from http://www.csd.abdn.ac.uk/publications/TR/2002/tr0207.pdf

23. Norman DA (1992) The Teddy, chapter 6 of the book: Turn signals are the facial expression of automobiles, Addison Weas- 
ley, but now out of print. Retrieved 14 Mar 2007, from http:// www.jnd.org/TurnSignals/TS-TheTeddy.html

24. Fleck M, Frid M, Kindberg, T, O’Brien-Strain, Eamonn, Rajani R, Spasojevic M (2002a) Rememberer: a tool for capturing museum visits. In: Proceedings of the ubiquitous computing conference (UbiComp 2002), pp 48-55

25. Gemmell J, Bell G, Lueder R (2006) MyLifeBits: a personal database for everything. Commun ACM 49(1):88-95

26. Beigl M (2000) MemoClip: a location-based remembrance appliance. Pers Technol 4:230-233

27. Dey AK, Abowd GD (2000) CybreMinder: a context-aware system for supporting reminder. In: Proceedings of handheld and ubiquitous computing (HUC'00), pp 172-186

28. DeVaul RW, Clarkson B, Pentland AS (nd) The Memory Glasses: Towards a Wearable, Context Aware, Situation-appropriate Reminder System, Retrieved 6 Oct, 2003, from the Citeseerwebsite: http://citeseer.nj.nec.com/493611.html

29. Schütte AA (1998) Patina: layering a history-of-use on digital objects, Masters thesis. MIT Media Laboratory, Cambridge

30. Harman J (2001) Creating a memory palace using a computer. In: Proceedings of the ACM conference on human factors in computing systems (CHI'01), pp 407-408

31. Harrison BL (2000) E-Books and the future of reading. IEEE J Comput Graph Appl, pp 32-39

32. Shen C, Lesh N, Vernier F (2003) Personal digital historian: story sharing around the table. Interactions, pp 15-22

33. Piernot PP, Felciano RM, Stancel R, Marsh J, Yvon M (1995) Designing the PenPal: blending hardware and software in a userinterface for children. In: Proceedings of the ACM conference on human factors in computing systems (CHI'95), pp 511-518

34. Balabanović M, Chu LL, Wolff GJ (2000) Storytelling with digital photographs. In: Proceedings of the ACM conference on human factors in computing systems (CHI'00), pp 564-571

35. De Verhalentafel (n.d.) Retrieved 14 Mar 2007 from De Waag's website: http://www.waag.org/verhalentafel (in Dutch and partly in English)

36. Greef P de, IJsselsteijn WA (2001) Social presence in a home tele-application. Cyberpsychol Behav 4:307-315

37. Mingo K, Dahiya R (2002) MemoryBox project, Retrieved 14 Mar 2007, from the Ivrea University website: http://projects.interaction-ivrea.it/endofyear/en/student/desire/memorybox.asp\#

38. Glos J, Cassell J (1997) Rosebud: technological toys for storytelling. In: Proceedings of the ACM conference on human factors in computing systems (CHI'97), pp 359-360

39. Multiple Intimate Media Environments (2001) Retrieved 14 Mar 2007, from: http://www.mimeproject.org

40. Frohlich DM, Murphy R (2000) The memory box. Pers Technol 4:238-240

41. Ullmer B (1997) Models and mechanisms for tangible user interfaces, Masters thesis. MIT Media Laboratory, Cambridge

42. British Telecom (2003) Seashell offers digital memories, Retrieved 14 Mar 2007 from BBCNews' website: http://news.bbc.co.uk/1/hi/technology/2985063.stm

43. Stevens MM, Abowd GD, Truong KN, Vollmer F (2003) Getting into the living memory box: family archives \& holistic design. Pers Ubiquitous Comput 7:210-216
44. Watson I, Marir F (1994) Case-based reasoning: a review. Knowledge Eng Rev 9(4):355-381

45. Hoven EAWH van den (2004) Graspable cues for everyday recollecting, Department of Industrial Design, Eindhoven University of Technology, The Netherlands ISBN 90-386-1958-8

46. González JA (1995) Autotopographies. In: Brahm G Jr, Driscoll $M$ (eds) Prosthetic territories: politics and hypertechnologies. Westview Press, Boulder, pp 133-150

47. Csikszentmihalyi M, Rochberg-Halton E (1981) The meaning of things: domestic symbols and the self. Cambridge University Press, Cambridge

48. Aarts E, Marzano S (2003) The new everyday, views on ambient intelligence. 010 Publishers, Rotterdam

49. Hoven E van den, Eggen B (2003) Digital photo browsing with souvenirs. In: Proceedings of the interact 2003, September 2003, Zurich, pp 1000-1003

50. Qian Y (2004) Data synchronization and browsing for home environments, Ph.D. thesis, Technische Universiteit Eindhoven, The Netherlands, ISBN 90-386-0832-2

51. Dijk EO (2004) Indoor ultrasonic position estimation using a single base station, Ph.D. thesis, Technische Universiteit Eindhoven, The Netherlands, ISBN 90-386-0912-4

52. Teixeira D, Verhaegh W, Ferreira M (2003) An integrated framework for supporting photo retrieval activities in home environments. In: Proceedings of the first european symposium on ambient intelligence (EUSAI 2003). Veldhoven, The Netherlands, pp 288-303

53. Fitzmaurice GW, Ishii H, Buxton W (1995) Bricks: laying the foundations for graspable user interfaces. In: Proceedings of the ACM conference on human factors in computing systems (CHI'95), pp 442-449

54. Ullmer B, Ishii H (2000) Emerging frameworks for tangible user interfaces. IBM Syst J 39(3/4):915-931

55. Fitzmaurice GW (1996) Graspable user interfaces, Ph.D. thesis, Department of Computer Science, University of Toronto

56. Glos J, Umaschi M (1997) Once upon an object... Computationally-augmented toys for storytelling. In: Proceedings of the international conference on computational intelligence and multimedia applications (ICCIMA'97), pp 245-249

57. Pemberton S (1999) The digital hug. Special issue of interactions, November and December 1999

58. Hoven E van den, Eggen B (2003) The design of a recollection supporting device: a study into triggering personal recollections. In: Proceedings of the HCI-Int. 2003, June 2003, Crete, part II, pp 1034-1038

59. Hoven E van den, Eggen B, Wessel I (2003) Context-dependency in the real world: how different retrieval cues affect Event-Specific Knowledge in recollections of a real-life event, SARMAC V, Aberdeen, July 2003

60. Sauzeon H, N'Khaoua B, Lespinet V, Guillem F, Claverie B (2000) Age effect in recall performance according to levels of processing, elaboration, and retrieval cues. Exp Aging Res 26:57-73 